\title{
Spectral bi-directional reflectance of snow and glacier ice measured in Dronning Maud Land, Antarctica
}

\author{
JAN-GUNNAR WINTHER \\ Norwegian Hydrotechnical Laboratory, SINTEF, N-7034 Trondheim, Norway
}

\begin{abstract}
Visible and near-infrared spectral reflectances of snow and superimposed ice were measured in Dronning Maud Land, Antarctica, during the 1992-93 austral summer. Spectral-reflectance curves of both snow and superimposed ice remain high $(>80 \%)$ in the visible region. A pronounced decrease in reflectance appears in the near-infrared, especially for superimposed ice. Superimposed ice with a $1 \mathrm{~cm}$ thick surface layer of ice-bound snow crystals had a considerably higher reflectance than superimposed ice containing only a few snow crystals. Furthermore, these data prove that snow and superimposed ice reflect solar radiation specularly and suggest that the anisotropy strengthens with increasing wavelengths. Integrated in-situ reflectances corresponding to Landsat TM bands $1-4$ show that TM band 1 is least affected, whereas TM band 4 is most affected by anisotropy. Furthermore, the anisotropy increases with increasing off-nadir viewing angles up to an angle corresponding to $90^{\circ}-\theta_{\mathrm{s}}\left(\theta_{\mathrm{s}}=\right.$ solar elevation $)$. For a $15^{\circ}$ off-nadir sensor-observation angle, the average snow reflectance for TM bands $1-4$ is about $10 \%$ higher than at nadir. Similarly, the apparent reflectance can be more than $50 \%$ higher than the nadir reflectance for larger observation angles. Consequently, if satellite-derived reflectances are going to be considered as absolute values, a topographic-correction model is needed to correct for the effects of anisotropy.
\end{abstract}

\section{INTRODUCTION}

Snow and ice cover large areas of the Earth's surface, especially in the polar regions. Snow and ice reflect solar radiation very efficiently such that little of the incoming solar radiation is absorbed at the surface in these regions. Even so, small changes in surface reflectance can affect the Earth-atmosphere energy balance (Warren and Wiscombe, 1985). Thus, it is clearly important to monitor and calculate the variability of the albedo of snow and ice. Then, accurate calculations of the energy exchange between snow and ice surfaces and the surrounding air mass can be carried out.

The reflectances of snow and glacier ice show a clear dependence on wavelength. The spectral-reflectance properties of snow have been studied and reported on by many investigators (Choudhury and Chang, 1979; Wiscombe and Warren, 1980; Warren, 1982; Zeng and others, 1984; Dozier, 1985; Dozier and others, 1988; Hall and others, 1992). Typically, the fraction of radiation reflected from fresh snow remains high in the visible region, while a distinct drop occurs in the near-infrared region of the electromagnetic spectrum. The albedo of snow drops below 0.10 in the mid-infrared region. In addition, snow of different degrees of metamorphism, as well as snow and glacier ice with different surface characteristics, can be separated since they exhibit distinctive spectral signatures. Satellites like Landsat TM (Thematic Mapper), NOAA AVHRR (Advanced Very High Resolution Radiometer) and SPOT (Système
Probatoire pour l'Observation de la Terre carry sensors that record surface reflectance within the visible and infrared wavelength regions. Consequently, satellite remote sensing enables studies to be made of surface characteristics such as topography, temperature, grainsize variations, melting areas and snow and glacier-ice facies (Orheim and Lucchitta, 1988; Winther, 1993).

The specular reflection of snow and glacier ice introduces a problem if the true spectral-response characteristics of such areas are going to be studied, for example, by satellite remote-sensing techniques. Freshly fallen snow can be considered a Lambertian reflector i.e. a perfect diffuse reflector) but, as snow metamorphoses, the specular component characterized as forward-scattering increases (Dirmhirn and Eaton, 1975; Steffen, 1987; Dozier and others, 1988; Hall and others, 1988, 1992). The specular properties of glacier (blue) ice are even more pronounced than for metamorphosed snow. Since many satellite sensors are nadir-viewing, the satellite will often provide a different reflectance compared to the hemispheric reflectance (or albedo) on the ground. For example, an image pixel directed such that it reflects incident radiation towards the satellite sensor can give too high a satellitederived ground reflectance due to anisotropy.

The main objectives of this study are to: (1) measure the spectral reflectance of snow and glacier ice, (2) estimate the bi-directional reflectance characteristics of snow and glacier ice, and (3) evaluate how sensitive the measured spectral reflectance is to varying observation angle. The latter can also serve as a measure of how 
sensitive satellite-derived reflectance is to surface topography. As an example, Landsat TM bands 1-4 reflectances have been calculated by integrating in-situ spectral reflectance measurements of snow and superimposed ice. Next, deviations from nadir reflectance are calculated for off-nadir observation angles of $15^{\circ}, 30^{\circ}$, $45^{\circ}, 60^{\circ}$ and $75^{\circ}$. Effects on the surface reflectance from varying solar elevation, solar azimuth, weather conditions and physical properties of snow and ice are not considered in this study.

\section{METHODS}

Visible and near-infrared spectral albedo measurements were acquired using the SE590 portable spectroradiometer that measures radiation between 370 and $1110 \mathrm{~nm}$ in 252 discrete steps. Each channel represents a band width of approximate $3 \mathrm{~nm}$. Spectral resolution of the sensor is about $10 \mathrm{~nm}$ and the field of view is $6^{\circ}$. The surface area seen by the sensor depends strongly on the observation angle and varies between about $20 \mathrm{~cm}^{2}$ (nadir) and $315 \mathrm{~cm}^{2}$ ( $75^{\circ}$ off-nadir) for the measurements presented here. The spectral detector head was fastencd to a standard camera tripod to avoid movements during the integration time of the sensor that was less than $1 \mathrm{~s}$. Immediately after each measurement sequence, a spectral measurement of a halon target at $0^{\circ}$ nadir angle was taken as a reference for the calculations of albedo. The solar and atmospheric conditions are considered stable during one scan sequence. The limits of sensitivity of the silicon detectors are reached in the near-infrared region and the signal-to-noisc ratio is small beyond $900 \mathrm{~nm}$ (Dozier and others, 1988; Hall and others, 1992). Therefore, only data between 370 and $900 \mathrm{~nm}$ are presented.

Scan sequences of bi-directional snow reflectance were acquired by pointing the spectral detector head at nadir $\left(0^{\circ}\right)$ and then at $15^{\circ}, 30^{\circ}, 45^{\circ}, 60^{\circ}$ and $75^{\circ}$ off-nadir followed by a nadir reference measurement of the halon target. Such a scan sequence typically took less than $2 \mathrm{~min}$. The horizontal direction of the measurements was towards the Sun.

Additionally, supporting measurements of air and snow temperature, snow density, liquid-water content, grain-size and shape, snow hardness and stratification were taken at each measuring site. The measuring sites were established within the area shown in Figure 1.

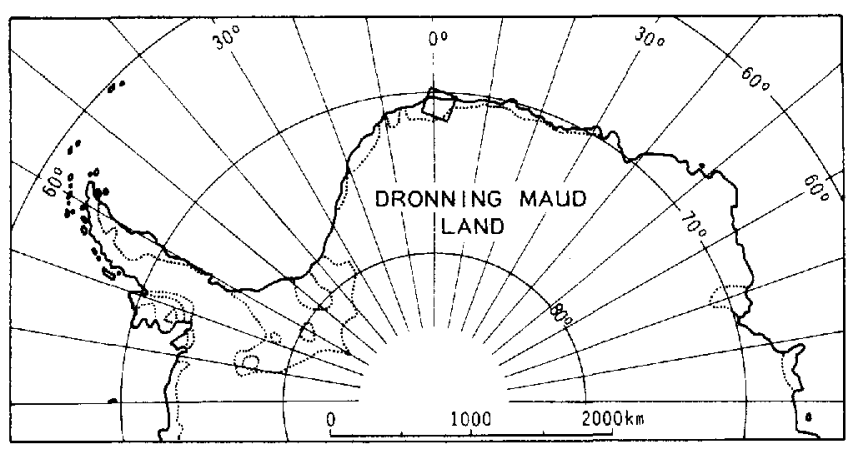

Fig. 1. Index map, showing the area where the measurements discussed in this paper were recorded. The dotted lines show the land boundary of the continent.

\section{RESULTS}

\section{Spectral reflectances of snow, superimposed ice and rock}

Figure 2 shows spectral-reflectance curves for snow, superimposed ice and rock taken on 16 January 1993 due west of the Norwegian Troll Station at $72^{\circ} 00.7^{\prime} \mathrm{S}$, $02^{\circ} 32.3^{\prime} \mathrm{E}$. The measuring site was located $1250 \mathrm{~m}$ a.s.l. at a glacier in Gjelsvikfjella. All reflectance curves were acquired within a distance of about $50 \mathrm{~m}$. It was partly cloudy during the measurements.

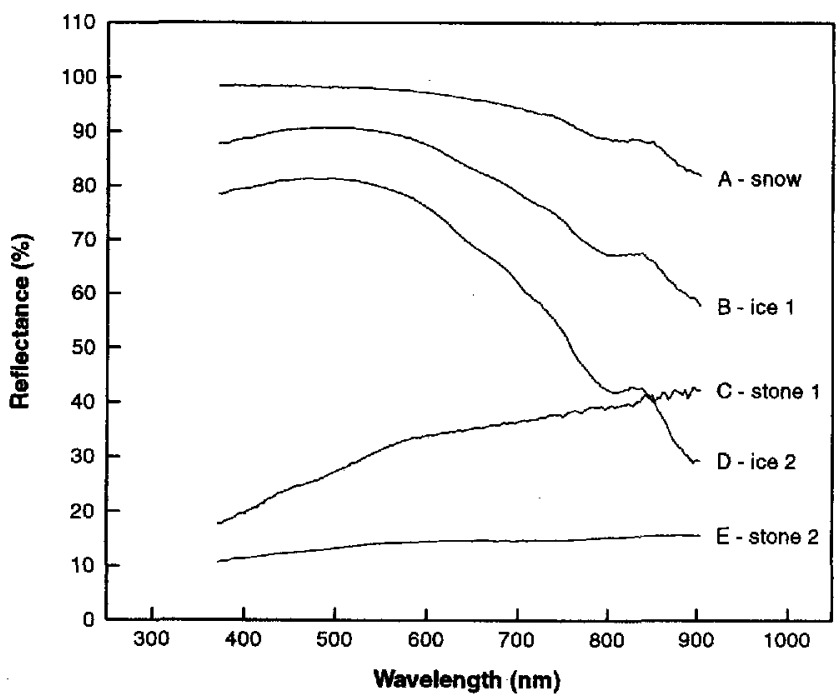

Fig. 2. Spectral reflectances of snow, superimposed ice and rock acquired on 16 January 1993 close to the Norwegian Troll Station at $72^{\circ} 00.7^{\prime} S, 02^{\circ} 32.3^{\prime} \mathrm{E}$. The curves show $A$, snow; $B$, superimposed ice where the upper $1 \mathrm{~cm}$ contained many ice-bound snow crystals giving a white appearance to the surface; $C$, bright part of a rock lying at the surface of the glacier; $D$, superimposed ice with many air bubbles but only a few ice-bound snow crystals; and $E$, dark part of the same rock as described above.

The characteristic snow-grain diameter for curve $\mathrm{A}$ was $0.8 \mathrm{~mm}$, ranging from about 0.2 to $1.2 \mathrm{~mm}$. Most snow crystals were rounded. Even so, the original edged cubic form could easily be seen when looking through a magnifying lens $(8 \times)$. Erosion and redistribution of snow grains took place at the surface due to the influence of wind forces. These winds produced a relatively compact snowpack with a density of $0.36 \mathrm{Mg} \mathrm{m}^{-3}$ at $5 \mathrm{~cm}$ depth. The snow temperature at $5 \mathrm{~cm}$ depth was $-4.6^{\circ} \mathrm{C}$ while the air temperature was $-3.8^{\circ} \mathrm{C}$. Overall, the snow surface was even, with a characteristic surface roughness of less than $1 \mathrm{~cm}$. As seen in Figure 2, the albedo is high and relatively stable in the visible region $(98 \%$ at $370 \mathrm{~nm})$ and then decreases moderately in the near-infrared. The albedo at $900 \mathrm{~nm}$ is 0.82 . This spectral signature is typical for fresh snow that has been moderately metamorphosed (7eng and others, 1984; Winther, 1993).

Supcrimposed ice forms when meltwater refreezes on the glacier surface. Curve D-ice 2 represents superimposed ice with a levelled surface containing many air bubbles and a few ice-bound snow crystals. Curve B-ice 1 represents superimposed ice where the upper $1 \mathrm{~cm}$ 
contains many ice-bound snow crystals. Thus, this surface had a white appearance that increased the albedo significantly (Fig. 2). Below this thin layer, the superimposed ice was similar to the ice represented by curve $D$ - ice 2. Curves B and D have considerably different signatures and higher reflectances than the spectral curves of glacier ice, congelation ice and refreezing ice reported by Zeng and others (1984).

Finally, Figure 2 displays two spectral-reflectance curves taken at a big rock that was situated at the surface of the glacier. This rock had two distinct parts. One was very bright (curve $\mathrm{C}$ - rock 1) while the other one was dark (curve $\mathrm{E}$ - rock 2). Interestingly, the near-infrared reflectance $(700-900 \mathrm{~nm}$ ) of curve $\mathrm{C}$ - rock 1 is not very different from that of superimposed ice, curve $\mathrm{D}-$ ice 2 .

\section{Bi-directional reflectance of snow}

Figure 3 shows the spectral reflectance of snow for viewing angles $0^{\circ}, 15^{\circ}, 30^{\circ}, 45^{\circ}, 60^{\circ}$ and $75^{\circ}$ for a viewing direction facing the Sun on 13 January 1993. 'I'his measurement site was at Jutulstraumen at $72^{\circ} 15.7^{\prime} \mathrm{S}$, $01^{\circ} 15.6^{\prime} \mathrm{F}$. The curves clearly prove the effect of anisotropic snow reflectance. Additionally, the anisotropy seems to increase slightly with increasing wavelengths. Reflectance values larger than 1.0 appear, especially for the largest viewing angles. Off-nadir reflectance values $>1.0$ are reported to be quite common for dry snow (Hall and others, 1992) but can also appear for wet snow (Dozier and others, 1988). This is because snow can reflect light specularly and more light may be reflected in one particular direction than by a Lambertian standard surface.

The snow at Jutulstraumen on 13 January had a characteristic grain-size diameter of $0.5 \mathrm{~mm}$, ranging from about 0.2 to $0.8 \mathrm{~mm}$. At a depth of $3 \mathrm{~cm}$ the snow density was $0.202 \mathrm{Mg} \mathrm{m}^{-3}$ while the corresponding snow temperature was $-2.2^{\circ} \mathrm{C}$. The surface was composed of freshly fallen snow that recently had been wind-blown and thus redistributed. Therefore, the snow consisted mainly of rounded snow crystals. Even so, some snow crystals appeared as needles and plates. There were no clouds in the sky during the measurements.

\section{Bi-directional reflectance of superimposed ice}

Figure 4 presents the spectral reflectance of superimposed ice for viewing angles $0^{\circ}, 15^{\circ}, 30^{\circ}, 45^{\circ}, 60^{\circ}$ and $75^{\circ}$ for a viewing direction facing the Sun on 16 January 1993. The measurements were taken close to the Norwegian Troll Station and at the same site as the reflectance curves given in Figure 2.

The spectral curve for the nadir viewing angle $\left(0^{\circ}\right)$ is identical with the curve $\mathrm{D}$ - ice 2 in Figure 2. Thus, the superimposed ice shown in Figure 4 contained numerous air bubbles but only a few ice-bound snow crystals. Overall, the ice was level with a small-scale surface roughness with vertical height variations of about $1 \mathrm{~cm}$.

Figure 4 illustrates that the specular properties of glacicr (superimposed) ice are relatively more prominent than those for snow (Fig. 3). For viewing angles $0^{\circ}, 15^{\circ}$, $30^{\circ}$ and $45^{\circ}$, the degree of anisotropy seems to be similar to that for snow and only moderately affected by

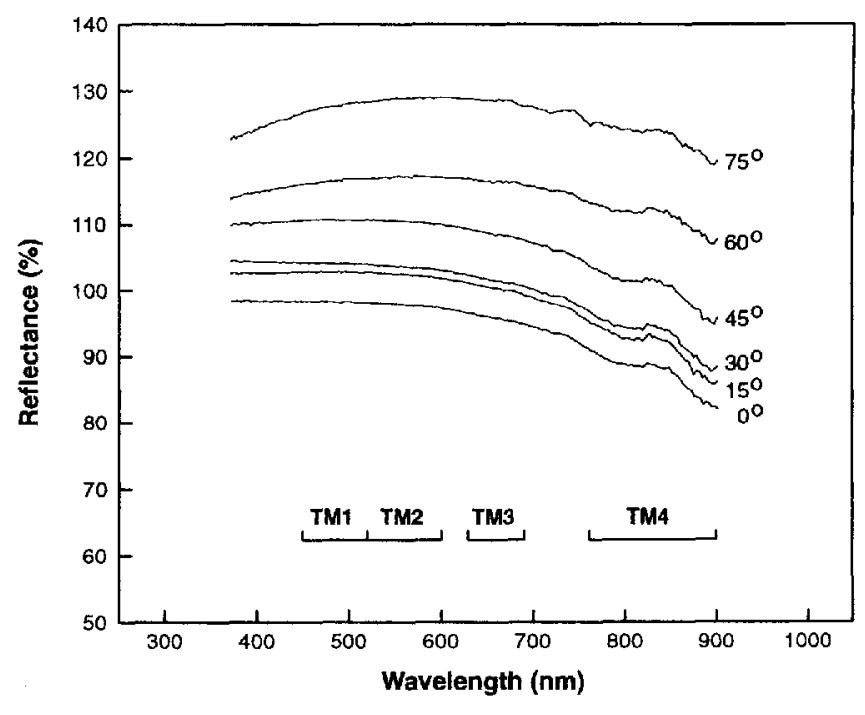

Fig. 3. Spectral reflectances of snow for viewing angles $\theta^{5}$, $15^{\circ}, 30^{\circ}, 45^{\circ}, 60^{\circ}$ and $75^{\circ}$ for a viewing direction facing the Sun on Jutulstraumen on 13 January 1993. The measuring site was located at $72^{\circ} 15.7^{\prime} \mathrm{S}, 01^{\circ} 15.6^{\prime} \mathrm{E}$. The wavelength regions of Landsat $T M$ bands $1-4$ are also shown. Note that the relative level of anisolropy is slightly sensitive to wavelength.

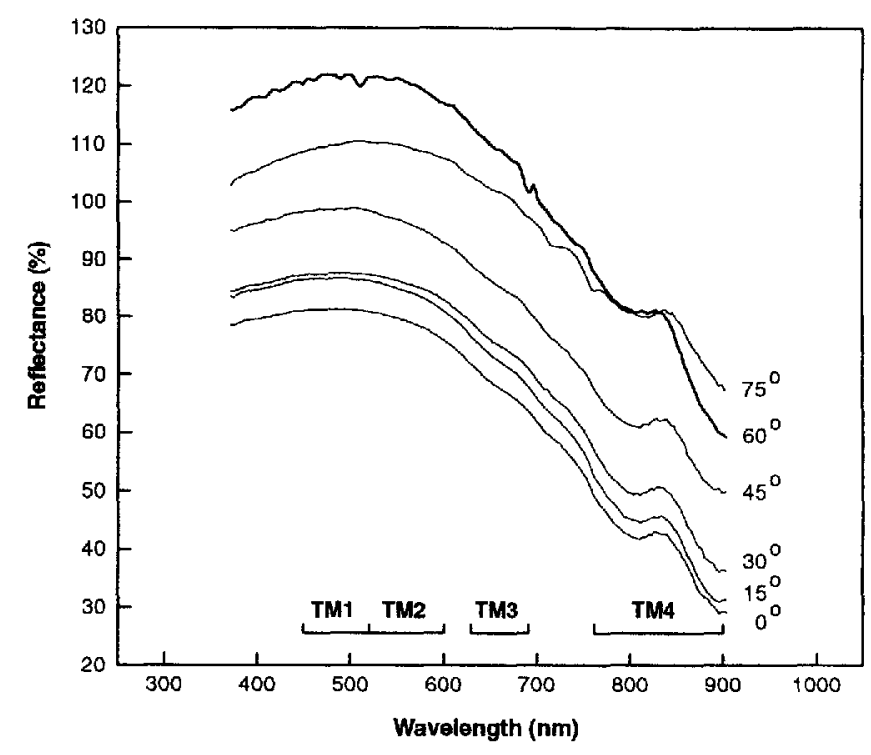

Fig. 4. Spectral-reflectance curves of superimposed ice for viewing angles $0^{\circ}, 15^{\circ}, 30^{\circ}, 45^{\circ}, 60^{\circ}$ and $75^{\circ}$ for a viewing direction facing the Sun. Measurements were laken on 16 January 1993 at $72^{\circ} 00.7^{\prime} \mathrm{S}, 02^{\circ} 32.3^{\prime} \mathrm{F}$, close to the Norwegian Troll Slation. The $60^{\circ}$ off-nadir abservationangle curve has the highest reflectance due lo its favourable angle relative to the Sun. The solar elevation was $31^{\circ}$ when the measurements were carried out.

wavelength. However, the $60^{\circ}$ off-nadir curve displays higher reflectance values than the $75^{\circ}$ off-nadir curve through the visible and up to about $840 \mathrm{~nm}$ in the nearinfrarcd wavelength region (Fig. 4). This can be explained by the strong specular properties of super- 
imposed ice and the solar elevation $\left(\theta_{\mathrm{s}}\right)$ that was $31^{\circ}$ at the time when the measurements were made. If it is assumed that the largest fraction of radiation was scattered in the forward direction, then the $60^{\circ}$ off-nadir observation angle $\left(90^{\circ}-\theta_{\mathrm{s}}\right)$ becomes the observation angle receiving most reflected solar radiation.

It is not obvious why the $60^{\circ}$ off-nadir curve decreases so rapidly in the near-infrared and even displays lower values than the $75^{\circ}$ off-nadir curve beyond about $840 \mathrm{~nm}$. One explanation could be the difference in surface area seen by the sensor in the two cases. The viewed surface area for the $60^{\circ}$ off-nadir spectral curve $\left(A_{60^{\circ}}\right)$ was about $86 \mathrm{~cm}^{2}$ while $A_{75}$ was $321 \mathrm{~cm}^{2}$. Thus, the larger area covered in the latter case could have had different spectral properties compared to the area seen by the sensor in the $60^{\circ}$ off-nadir position. The data have not been corrected for this effect.

\section{TM bands $1-4$ reflectances}

TM bands 1-4 reflectances are calculated by integrating in-situ nadir spectral-reflectance measurements. Next, deviations for $15^{\circ}, 30^{\circ}, 45^{\circ}, 60^{\circ}$ and $75^{\circ}$ off-nadir observation angles are computed. Table 1 summarizes these calculations based on 22 spectral-scan measurements of snow and nine spectral scans of superimposed ice. The reflectance data may be used to study the strength of anisotropic reflectance for each TM band. In addition, the data show how the anisotropic reflectance varies with varying observation angle. The latter can also serve as a measure of how sensitive TM bands 1-4 reflectances are to surface topography. Obviously, the reflectance received by a sensor for a given viewing anglc and surface topography depends strongly on the solar elevation $\left(\theta_{s}\right)$.

Table 1 shows that the anisotropic reflectance of snow and superimposed ice increases with increasing wavelengths. For example, TM band 4 appears more sensitive

Table 1. TM bands $1-4$ reflectances and their sensitivity to varying observation angle. Numbers are deviations (in per cent) from nadir reflectance for off-nadir observation angles $(\beta)$ of $15^{\circ}, 30^{\circ}, 45^{\circ}, 60^{\circ}$ and $75^{\circ}$. The data are computed from 22 spectral-scan measurements of snow and nine spectral scans of superimposed ice

\begin{tabular}{lrrrrr}
\hline & $\beta$ & TM1 & TM2 & TM3 & TM4 \\
\hline \multirow{4}{*}{ Snow } & $15^{\circ}$ & 9.15 & 9.88 & 10.87 & 12.76 \\
& $30^{\circ}$ & 21.58 & 24.92 & 28.39 & 33.99 \\
& $45^{\circ}$ & 25.38 & 28.36 & 31.43 & 37.89 \\
& $60^{\circ}$ & 39.47 & 44.40 & 50.05 & 60.33 \\
& $75^{\circ}$ & 29.99 & 31.78 & 34.26 & 40.97 \\
Super- & $30^{\circ}$ & 9.02 & 9.81 & 11.66 & 17.71 \\
imposed & $45^{\circ}$ & 21.50 & 21.70 & 25.84 & 48.73 \\
ice & $60^{\circ}$ & 49.41 & 52.21 & 60.17 & 90.66 \\
& $75^{\circ}$ & 35.29 & 38.60 & 49.55 & 96.53 \\
& & & & & \\
\hline
\end{tabular}

to anisotropic reflectance than TM bands $1-3$. This may be the reason why higher TM band 4 rather than TM band 2 reflectances are found in the works by Hall and others (1988, 1990) and Winther (1993).

Furthermore, each of the four wavelength regions corresponding to TM bands $1-4$ shows increasing anisotropy with increasing off-nadir observation angles up to an angle of $90^{\circ}-\theta_{\mathrm{s}}$. For the measurements presented here the peak in anisotropy is at about $60^{\circ}$. Most radiation will be reflected at this angle because of the forward-scattering propertics of the surface and the solar elevation of approximate $30^{\circ}$. Snow reflects about $10 \%$ (avcrage of TM bands $1-4$ ) more radiation at the $15^{\circ}$ off-nadir observation angle than at nadir (Table 1). Similarly, snow has $49 \%$ higher reflectance at the $60^{\circ}$ offnadir viewing angle than at nadir.

\section{CONGLUSIONS}

Visible and near-infrared reflectances of snow and superimposed ice show a clear dependence on wavelength. The reflectance decreases moderately with wavelength in the visible region while the reduction becomes more prominent in the near-infrared. Superimposed ice with a $1 \mathrm{~cm}$ thick surface layer of ice-bound snow crystals has significantly higher reflectance than superimposed ice containing only a few ice-bound snow crystals.

Snow reflects solar radiation specularly. In addition, the anisotropic properties of snow seem to strengthen for increasing wavelengths. Reflectance values larger than 1.0 appear, since more light can be reflected than is incident upon the snow in one particular direction. Superimposed ice is a more efficient specular reflector than snow. The sensor-observation angle giving the highest reflectance depends on solar elevation $\left(\theta_{s}\right)$ and surface topography. These data show a clear peak in reflectance for the $60^{\circ}$ off-nadir viewing angle that corresponds to an angle of approximate $90^{\circ}-\theta_{\mathrm{s}}$.

Integrated in-situ spectral reflectances of snow and superimposed ice show that TM bands $1-4$ are affected by anisotropic surface reflectance. The anisotropy increases with increasing wavelengths, i.e. TM band $l$ is least affected while TM band 4 is most affected. Furthermore, the reflectances corresponding to TM bands 1-4 show an increasing anisotropy for increasing off-nadir viewing angles up to $90^{\circ}-\theta_{\mathrm{s}}$. For a sensor viewing angle $15^{\circ}$ offnadir, the snow reflectance is about $10 \%$ higher than at nadir while it can excced $50 \%$ for larger off-nadir viewing angles. Consequently, satellite-derived albedo of metamorphosed snow can deviate considerably from the true spectral response of these surfaces. If satellite-derived albedos are going to be considered as absolute values, a topographic model is needed to correct for the effects introduced by anisotropy.

\section{ACKNOWLEDGEMENTS}

The author would like to thank all the participants on the Norwegian Antarctic Research Expedition 1992-93. J. O. Hagen at the Norsk Polarinstitut is particularly acknowledged for being generous with his time and allowing this 
experiment to be undertaken. This is publication No. 119 of the Norwegian Antarctic Research Expeditions.

\section{REFERENGES}

Choudhury, B.J. and A. T.C. Chang. 1979. Two-strcam theory of reflectance of snow. IEEE Transactions on Geoscience Electronics, GE17(3), 63-68.

Dirmhirn, I. and F. D. Eaton. 1975. Some characteristics of the albedo of snow. 7. Appl. Meteorol, 14(3), 375-379.

Dozier, J. 1985. Spectral signature of snow in visible and near-infrared wavelengths. In Proceedings of the 3rd International Colloquitim on Spectral Signalures of Objects in Remote Sensing. Paris, European Space Agency, 437-442. (SP-287.)

Dozier, J., R.E. Davis, A.T.C. Chang and K. Brown. 1988. The spectral bidirectional reflectance of snow. In Proceedings of the $4 \mathrm{th}$ International Colloquium on Spectral Signatures of Objecls in Remote Sensing. France, European Space Agency, 87-92. (SP-247.)

Hall, D. K., A. T. C. Chang and H. Siddalingaiah. 1988. Reflectances of glaciers as calculated using Landsat-5 Thematic Mapper data. Remote Sensing Environ., 25, 311-321.

Hall, D. K., R. A. Bindschadler, J. L. Foster, A. T. C. Chang and H. Siddalingaiah. 1990. Comparison of in situ and satellite-derived reflectances of Forbindels Glacier, Greenland. Int. J. Remote Sensing, $11(3), 493 \cdot 504$.

Hall, D. K., J. L. Foster and A. T. C. Chang. 1992. Reflectance of snow as measured in-situ and from space in sub-Arctic areas in Canada and Alaska. IEEE Trans. Geosci. Remote Sensing, 30(3), 634-637.

Orheim, O. and B. K. Lucchitta. 1988. Numcrical analysis of Landsat Thematic Mapper images of Antarctica: surface temperatures and physical properties. Ann. Glaciol., 11, 109.120.

Steffen, K. 1987. Bidirectional reflectance of snow at $500-600 \mathrm{~nm}$. International Association of Hydrological Sciences Publication 166 (Symposium at Vancouver 1987 -Large Scale Effects of Seasonal Snow Cover ), $415-425$.

Warren, S. G. 1982. Optical properties of snow. Rev. Geophys. Space Phys., $20\{1), 67-89$

Warren, S. G. and W.J. Wiscombe. 1985. Dirty snow after nuclear war. Nature, 313(6002), 467-470.

Winther, J.G. 1993. Landsat TM derived and in situ summer reflectance of glaciers in Svalbard. Polar Research, 12(1), 37-55.

Wiscombe, W.J. and S. G. Warren. 1980. A model for the spectral albedo of snow. I. Pure snow. J. Atmos. Sci., 37(12), 2712-2733.

Zeng, Q., M. Cao, X. Feng, F. Liang, X. Chen and W. Sheng. 1984. A study of spectral reflection characteristics for snow, ice and water in the north of China. International Association of Hydrological Sciences Publication 145 (Symposium at Hamburg - Hydrological Applications of Remote Sensing and Remote Data Transmission), 451-462.

The accuracy of references in the text and in this list is the responsibility of the author, to whom queries should be addressed. 